\title{
Comparative Analysis of Cloud Computing Sector Based on Listed Companies
}

\author{
Ni Ruan ${ }^{\mathrm{a}}$, Hai-ping Huang ${ }^{\mathrm{b},{ }^{*}}$ and Huan Deng ${ }^{\mathrm{c}}$ \\ Mathematics and Information Science Department, Guangxi College of Education, Nanning 530023, \\ Guangxi, China \\ aruanni-815@163.com, bhuanghaiping505@qq.com \\ ${ }^{*}$ Corresponding author: Hai-Ping HUANG
}

Keywords: Cloud computing, MA,MACD, Comparative analysis.

Abstract. This paper tested the MACD and MA expert systems of securities trading software with the statistical empirical analysis method based on the real and open securities cloud computing sector data. And it also conducted a comparative analysis of the MACD and MA trend indicators based on the theory of mathematical statistics with the annual net profit margin, rate of return and winning percentage as the management objectives. The results showed that annual rate of return and net profit margin of the MACD expert system was $215.41 \%$ and $215.25 \%$ of that of the MA expert system respectively, and the risk of the two expert systems was almost the same. Investors should choose the MACD expert system for the cloud computing sector.

\section{Introduction}

As an approach to securities investments, technical analysis is performed to predict change tendencies of market prices by analyzing market behaviors. It focuses on drawing figures or graphs in a chronological order or establishing some index systems based on data about daily transactions in stock market, including price fluctuations, changes to trading volume and open interest. Then, analysis and research are performed based on these figures, graphs or index systems to forecast tendencies o stock prices. Computers are so popular that they can be used for analyzing securities and concluding transactions of all securities investors. At present, MA, MACD is a common expert system of software for analyzing securities. Generally known as an index system, it is theoretically based on Dow Jones' “average cost concepts”. For the management objectives of win rate, annual rate of return and net profit margin, data about listed companies' cloud computing were statistically tested and practicality of MA, MACD was analyzed.

Proposed by Geral Appel in 1979 [1], MACD is calculated based on the difference between fast and slow exponential moving averages (EMAs). Here, "fast" and "slow" imply short-term and long-term EMAs respectively. 12-Day and 26-day EMAs are the most common.

The mathematical formula of MACD is as follows [2]:

MACD=12-daysEMA - 26-daysEMA

The mathematical formula of EMA is written as follows :

$\mathrm{EMA}_{\text {today }}=\frac{p_{1}+(1+\alpha) p_{2}+(1+\alpha) p_{3}+(1+\alpha) p_{4}+\ldots}{1+(1+\alpha)+(1+\alpha)+(1+\alpha)+\ldots}$

$\alpha=\frac{2}{N+1} \quad N$ is number of periods.

Where, $p_{i}(i=1,2, . ., n)$ is closing price on the $i^{\text {th }}$ day and $n$ is number of periods in a moving average forecast.

The formula of the moving average Ma [3] is: 
$M A=\frac{c_{1}+c_{2}+\Lambda \Lambda+c_{n}}{n}$

Where, $c_{i}(i=1,2, \Lambda, n)$ is the $\mathrm{i}$-th day of closing price, and $n$ is the moving average cycle.

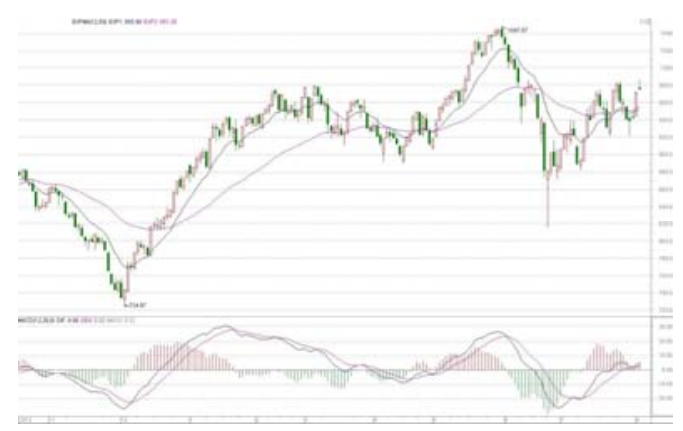

Fig.1 MACD expert system

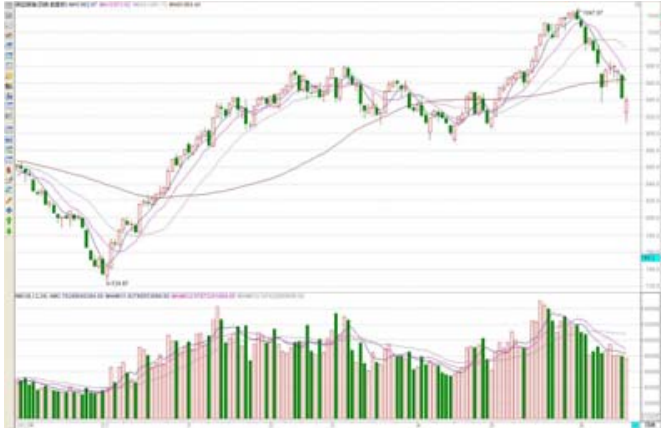

Fig.2 MA expert system

\section{Empirical Analysis of MACD (Fig 1)}

\section{Experiments and Results}

(1) Experimental Procedures

MACD is based on basic practices.

Golden cross of MACD: DIFF (Differential) exceeds DEA bottom up, which suggests that stocks shall be bought.

Dead cross of MACD: DIFF goes beyond DEA in a top-down manner, which means stocks shall be sold.

MACD histogram (green to red): Negative MACD value becomes positive, and short position turns into long position in the stock market.

MACD histogram (red to green): Positive MACD value gets negative, and long position changes into short position in the stock market.

When DIFF and DEA are positive, namely they are above the neutral axis, long position will be dominant in the stock market, and stocks can be bought as long as DIFF exceeds DEA.

The short position will be dominant in the stock market and DIFF will decline beyond DEA in case that both DIFF and DEA are negative (below the neutral axis), which indicates that stocks shall be sold.

The situation will be reversed when DEA and $\mathrm{K}$ tend to deviate from each other.

Error rate will be relatively high in DEA during market correction, whereas deficiencies may be appropriately made up in combination with RSI and KDJ.

Source Codes of MACD

LONG 1020026

SHORT 220012

M 22009

DIFF:=EMA(CLOSE,SHORT) - EMA(CLOSE,LONG);

DEA := EMA(DIFF,M);

MACD := 2*(DIFF-DEA);

ENTERLONG:CROSS(MACD,0);

EXITLONG:CROSS(0,MACD);

(2)Experimental platform: Great Wisdom Software (Version 5.99), Guosheng Securities

(3) Experimental parameters: close out or open a position just for once for funds that meet related standards and the trading costs shall be $0.5 \%$ of the funds. 
(4) Experimental samples: daily data about cloud computing from March 2016 to April 2017.

(5) Experimental processes, time and results:

Table1 Test Results of MACD

\section{Setting of System Test}

Test method: technical indicator - MACD

Test time: from $1^{\text {st }}$ March 2016 to $11^{\text {th }}$ April 2017, Measurements for Forced Close-out

Number of Tested Stocks: 57 Initial Investments: RMB40,000.00

Requirements for buy:

The stocks shall be bought in any of following cases:

1. All following requirements are met.

1.1. Technical indicator: DIFF of MACD $(12,26,9)$ goes upwards above the DEA (moving average)

If the above technical indicator is reached, all funds can be invested in buying stocks at average or closing price.

In case of any continuous signal, investors are not suggested to buy more.

Requirements for selling: none

Requirements for closing position: closed out at closing price

Indicator for stock selection: technical indicator: DIFF of MACD (12, 26, 9) goes downwards below the DEA (moving average)

\section{Summary of System Test Report}

Quantity of Tested Stocks: $\quad 57 \quad$ Annual Rate of Return $\quad$ 19.15\% $\quad$ Trades per Year: $\quad 444.00 \quad$ Win Rate: $\quad 45.53 \%$

Success Rate: $\quad$ 45.53\% Average Revenues: $\quad$ RMB983.49 $\quad$ Signals per Year: $\quad 888.00$

Maximum Profits from a Trade: RMB27,758.31

Maximum Losses from a Trade: RMB-8,540.42

Number of Trades: $\quad 481 \quad$ Number of Profit Trades: 219

Net Profits: $\quad$ RMB473,059.00 Net Margin: 20.75\%

Net Profits from Simple Stock Holdings: $\quad$ RMB178,446.41

Net Margin of Simple Stock Holdings: $\quad 7.83 \%$

Net Profits from Ideal Models: $\quad$ RMB27,285,252,096.00

Net Margin of Ideal Models: $\quad 1,196,721.63 \%$

\section{Empirical analysis of MA expert system (see Fig.2)}

\section{Experiment and result}

(1) Experimental program:

The expert system MA is developed in accordance with Granville's eight rules. The transaction rule is: MA(10) line is added to MA(5) line to form the golden cross buy-in. MA(30) line is destroyed by MA(10) line to form the death cross sell-out [2].

Source code of the MA expert system

SHORT 1305

LONG 510030

CROSS(MA(CLOSE,SHORT),MA(CLOSE,LONG))

CROSS(MA(CLOSE,LONG),MA(CLOSE,SHORT))

ENTERLONG:CROSS(MA(CLOSE,SHORT),MA(CLOSE,LONG));

EXITLONG:CROSS(MA(CLOSE,LONG),MA(CLOSE,SHORT))

(2) Experimental platform: V5.99 of the great wisdom securities information platform

(3) Experimental parameters: one-time position building or full liquidation of funds meeting conditions, taking $0.5 \%$ of transaction costs.

(4) Experimental samples: date line data of the cloud computing block (March 2016 - April 2017)

(5) Experimental process, time and results: 
Table2 Test results of MA expert system

\section{System test setting}

Test method: technical index - MA

Test time: March 1, 2016 - April 11, 2017 Calculation of the forced liquidation

Test stock: 57 in total Initial input: 40,000.00yuan

Buy-in conditions:

One of the following conditions is valid:

1. The following conditions are valid at the same time

1.1 Technical index: MA (5, 10, 20, 30, 120, 250) indicatrix MA1 crosses upward MA2 [moving average]

When conditions are valid: according to the middle price, buy in with all funds at the closing price

In case of continuous signals: no more buy-in

Sell-out conditions: no sell-out condition

Liquidation conditions: (close a position according to the closing price)

Index-based stock selection: technical index: MA (5, 10, 20, 30, 120, 250) indicatrix MA2 crosses downward MA3

[moving average]

Number of tested stocks: 57

Annual rate of return: $8.89 \%$

Winning rate: $43.16 \%$

Average profit: 589.01yuan

Maximum single profit: 18,105.90yuan Maximum single loss: -16,139.78yuan

Transaction times: $373 \quad$ Profitable transaction times: 161 (accounting for $43.16 \%$ )

Net profit: 219,701.50yuan Net profit rate: $9.64 \%$

Simple possessed net profit: 178,446.41 Simple possessed net profit margin: $7.83 \%$

Ideal model net profit: 27,285,252,096.00yuan

Ideal model net profit rate: 1,196,721.63\%

\section{Result analysis}

Table3 Comparative analysis sheet

\begin{tabular}{|c|c|c|c|c|}
\hline & Winning rate & $\begin{array}{c}\text { Annual rate of } \\
\text { return }\end{array}$ & Net profit margin & $\begin{array}{c}\text { Annual transaction } \\
\text { times }\end{array}$ \\
\hline MACD expert system & 45.53 & 19.15 & 20.75 & 444.00 \\
\hline MA expert system & 43.16 & 8.89 & 9.64 & 344.31 \\
\hline $\begin{array}{c}\text { Ratio of MACD results and } \\
\text { MA results }\end{array}$ & $105.49 \%$ & $215.41 \%$ & $215.25 \%$ & $128.95 \%$ \\
\hline
\end{tabular}

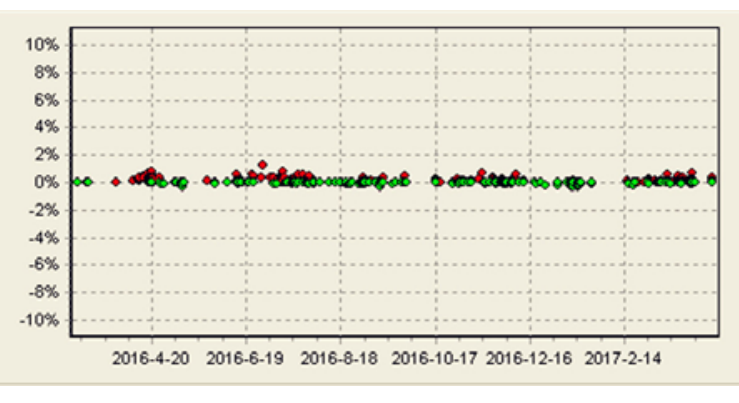

Fig.3 Annual MACD transaction times

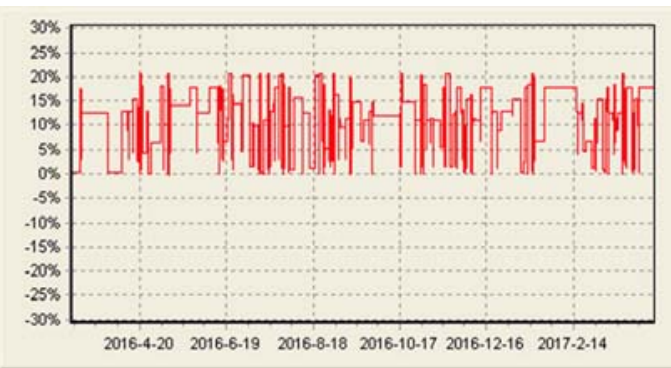

Fig.4 MACD earnings curve 


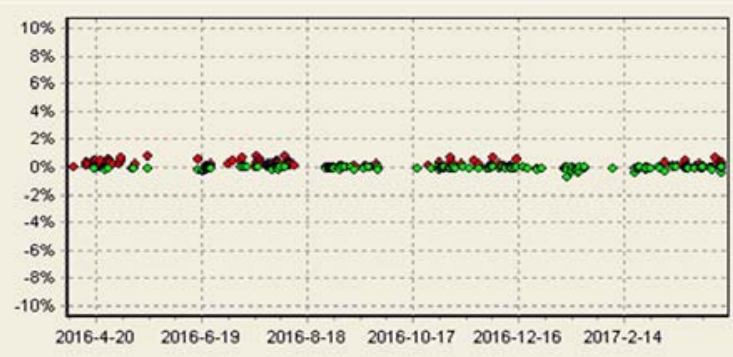

Fig.5 Annual MA transaction times

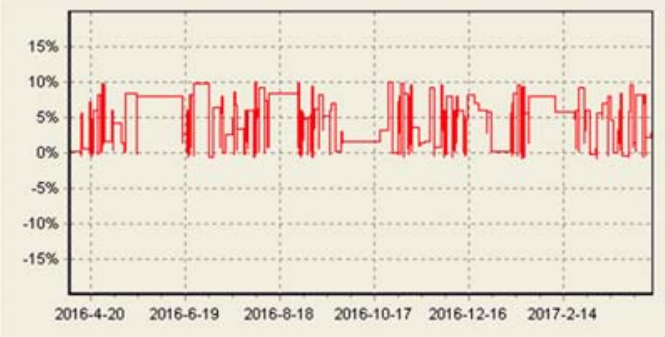

Fig.6 MA earnings curve

\section{Conclusion}

This paper analyzed the practicality of the MACD and MA expert systems with winning percentage, annual rate of return and net profit margin, a major concern among the investors, as the management objectives [4-6]. The annual rate of return and net profit margin of the MACD expert system is $215.41 \%$ and $215.25 \%$ of that of the MA expert system, indicating that the MACD expert system could bring $215.41 \%$ and $215.25 \%$ of return than the MA expert system in guiding the cloud computing sector investment. In addition, the winning percentage of the MACD expert system is about 1 times more than that of the MA expert system, indicating that the risk of the two investment options is the same. Almost twice the annual rate of return and net profit margin indicates that investors should choose the MACD expert system for the cloud computing sector. Although the winning percentage is $45.53 \%$, it is an optional investment program for investors who like pursing high profits and are willing to take risks.

\section{Acknowledgement}

This research was financially supported by the Education Department of Guangxi Province (NO.KY2016YB579), and scientific research projects of Guangxi College of Education in 2015 (NO.A2015001,NO.B2015001,NO.B2015006), and 2017 Key Program for Education and Teaching Reform of Guangxi College of Education (NO.XJJG17A09).

\section{References}

[1] Information on http://wiki.mbalib.com/wiki/\%E5\%B9\%B3\%E6\%BB\%91\%E5\%BC\%82\%E5\% 90\%8C\%Е7\%A7\%BB\%E5\%8A\%A8\%E5\%B9\%B3\%E5\%9D\%87\%E7\%BA\%BF.

[2] Information on http://forex-indicators.net/macd.

[3] Information on http://en.wikipedia.org/wiki/Moving_average.

[4] Y. Liu: Empirical Study on Senior Managers and Performances in Companies of High-Tech based on SPSS Software Regression Analysis, Journal of software. 7(7)1569-1576.

[5] Y. M. Wang: Application of Moving Average in Stock Market, Zhejiang Statistics(in Chinese), 2(1998) 25.

[6] Y. B. Cao: Application of MACD Index in Securities Investment, Manager’s Journal(in Chinese), 4(2010)166-167. 